\title{
Effect of the Hydraulic Characteristics of a Stream Channel and its Surroundings on the Runoff Hydrograph
}

V. Matoušek

The course and magnitude of a rainfall flood depends primarily on the intensity and duration of the rainfall event, on the morphological parameters of the watershed (e.g. its slope and shape), and on how to watershed has been exploited. A flood wave develops in the stream channel that drains the watershed, and it transforms while passing along the channel. This is particularly the case if the water spreads into floodplains and/or storage reservoirs while passing through the channel. This paper addresses an additional effect that has a significant influence on the magnitude and course of the flood wave but has not previously been addressed adequately, namely the effect of the hydraulic parameters of the stream channel itself on the transformation of a flood wave. The paper explains theoretically and shows on a practical example that a smooth channel with a high capacity significantly increases the magnitude and speed of a flood wave.

Many flood events are unnecessarily severe just because the watershed is drained by a hydraulically inappropriate channel. The channel is large and smooth and therefore it gathers most of the flowing water during the flood event, producing high water velocity in the channel. As a result, the large and smooth channel accelerates the runoff from the watershed and constrains the spread of water into the floodplain. A high and steep flood wave is developed in the channel, and this floods areas with a limited water-throughput capacity (e.g. urban areas in the vicinity of hydraulic structures) downstream the channel. This paper offers a methodology for evaluating the ability of a channel to convey a flood wave safely and for recognizing whether a regulated channel should be subjected to restoration due to its inability to convey flood waves safely.

Keywords: rainfall-runoff process, runoff velocity, flood-wave transformation, flood damping, stream channel restoration.

\section{Introduction}

In the part of central Europe that is now the Czech Republic, the effect of an artificial channel of high capacity on the runoff culmination discharge was already under discussion more than a century ago, during implementation of the General Program of River Regulation in the Kingdom of Bohemia, which started in 1903. It was claimed that river regulation concentrates water into a river channel and constrains the spread of water into floodplains, resulting in amplification of the flood wave. To suppress this effect, the Program suggested building storage reservoirs on regulated rivers. Nowadays, changing the floodwave hydrograph caused by the spread of water into a floodplain or into a storage reservoir is discussed in standard hydrology textbooks, e.g. [1], [5], together with methods for describing this phenomenon.

However, transforming the flood wave due to the spread of water into a floodplain or into a storage reservoir is only one part of the problem. The other is the formation of a flood wave due to the channel itself. This effect has not yet been addressed adequately.

For drainage purposes, many small natural channels crossing crop fields have been regulated to artificial, straight, deep, smooth channels of unnecessarily high capacity. Such channels accelerate the runoff process, the runoff hydrograph transforms (it becomes steeper) and the culmination discharge increases. This paper offers a theoretically based methodology for evaluating the runoff discharge during a flood event in a watershed drained by both artificial and natural (restored) channels. The methodology should help to evaluate the function of a channel during flooding and to decide whether an artificial channel should be subjected to restoration. The proposed methodology is based on the standard method of isochrones.

\section{Theoretical analysis}

\subsection{Survey of the flow routing method, producing a theoretical hydrograph}

One of the most efficient overland flow routing methods is the time-area method [1]. This method omits storage effects and divides the watershed into subareas, using isochrones. An isochrone is a contour which passes through points of the same travel time of a water particle from the location given by the point to the location of the outlet of the watershed.

To construct isochrones, it is first necessary to determine the average travel time of a water particle. This is accomplished by using empirical formulae calculating the travel time through the hydraulic length of the watershed from the surface flow velocity deduced for the hydraulic properties of the watershed surface, and from the channel flow velocity using the Manning equation for the channel draining the watershed.

Isochrones of constant travel times are drawn on to a map of the watershed. The area of each zone is then determined by a planimeter, and the area values are used for determining the runoff discharge in the outflow profile of the watershed (see Fig. 1). The time-area method calculates the zonal runoff from the zone area and from the excess (effective) rainfall. The equation for the zonal runoff discharge, $Q_{t}$, reads

$$
Q_{t}=F_{t} k_{0} H_{t} \frac{10^{3}}{60 t}\left(\mathrm{~m}^{3} / \mathrm{s}\right)
$$

In the equation, $F_{t}$ is the area bordered by the isochrone associated with the time period $t$ in $\mathrm{km}^{2}, k_{0}$ is the coefficient of direct runoff, $H_{t}$ is the total magnitude of rainfall in mm over the time period $t$, and $t$ is the time period in minutes from the beginning of the rain. 
Eq. 1 contains the runoff coefficient $k_{0}$, a dimensionless empirical coefficient related to the abstractive and diffusive properties of the catchment. Its value is influenced by many parameters associated with the properties of the evaluated watershed and it is very difficult to determine the value accurately. However, the objective of this paper is to analyze the effect on a rainfall flood of channel properties, rather than watershed properties. Therefore an investigation into appropriate values of the coefficient is not a part of the analysis described here. The same value of the coefficient is taken for different stream channels.

\subsection{Basics of the proposed methodology: an evaluation of the effect of the velocity in the stream channel on the theoretical hydrograph}

Imagine that the same watershed as in Fig. 1 is drained by a stream channel that is reclaimed in such a way that the mean velocity of the water in the reclaimed channel is twice that considered in Fig. 1. The higher velocity in the channel has a profound effect on the course of the isochrones (see Fig. 2). This is due to the shorter travel time in the channel (the travel time in the terrain of the watershed remains unchanged).

In Fig. 2, the new isochrones are drawn as dotted lines. The new lines (representing the isochrones for the channel velocity that is twice the velocity in the original channel before adaptation) match the original lines at the border of the watershed, because the travel time of the water in the terrain is the same for both situations. The difference in the shapes of the isochrones for a certain travel time is greatest at the location where the isochrones cross the stream channel. For the new velocity in the channel, the dotted line for a certain travel time must match the dashed line of the travel time that is one half of that of the dotted line. For example, the dotted line representing the 10-minute isochrone must match the dashed line representing the 20-minute isochrone at the location where both isochrones cross the stream channel (see Fig. 2). The comparison of the hydrographs for the two situations in Figure 2 shows that the hydrograph grows faster if the velocity in the channel is higher. In other words, higher velocity in the channel creates a steeper hydrograph.
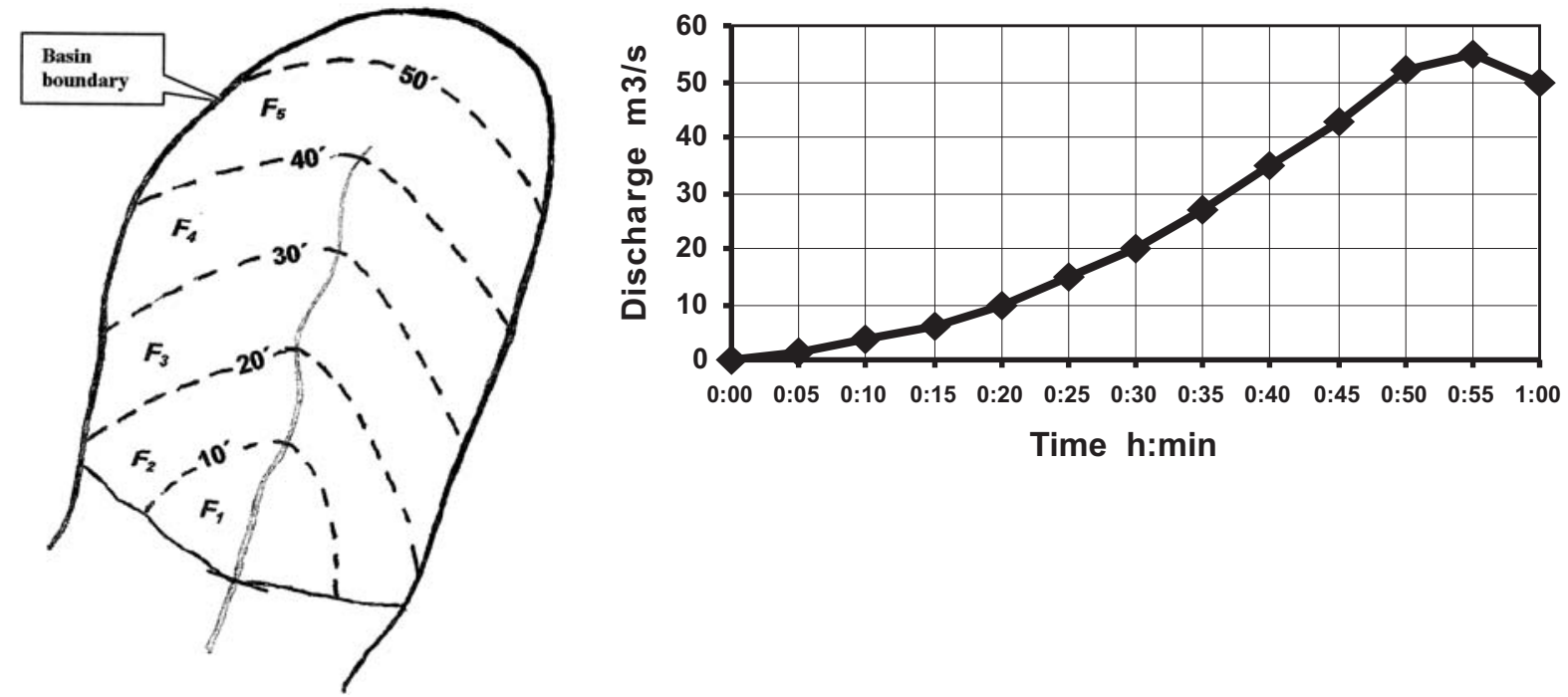

Fig. 1: Isochrones in a watershed, and the constructed ascending part of a hydrograph (flood wave) in an outflow profile
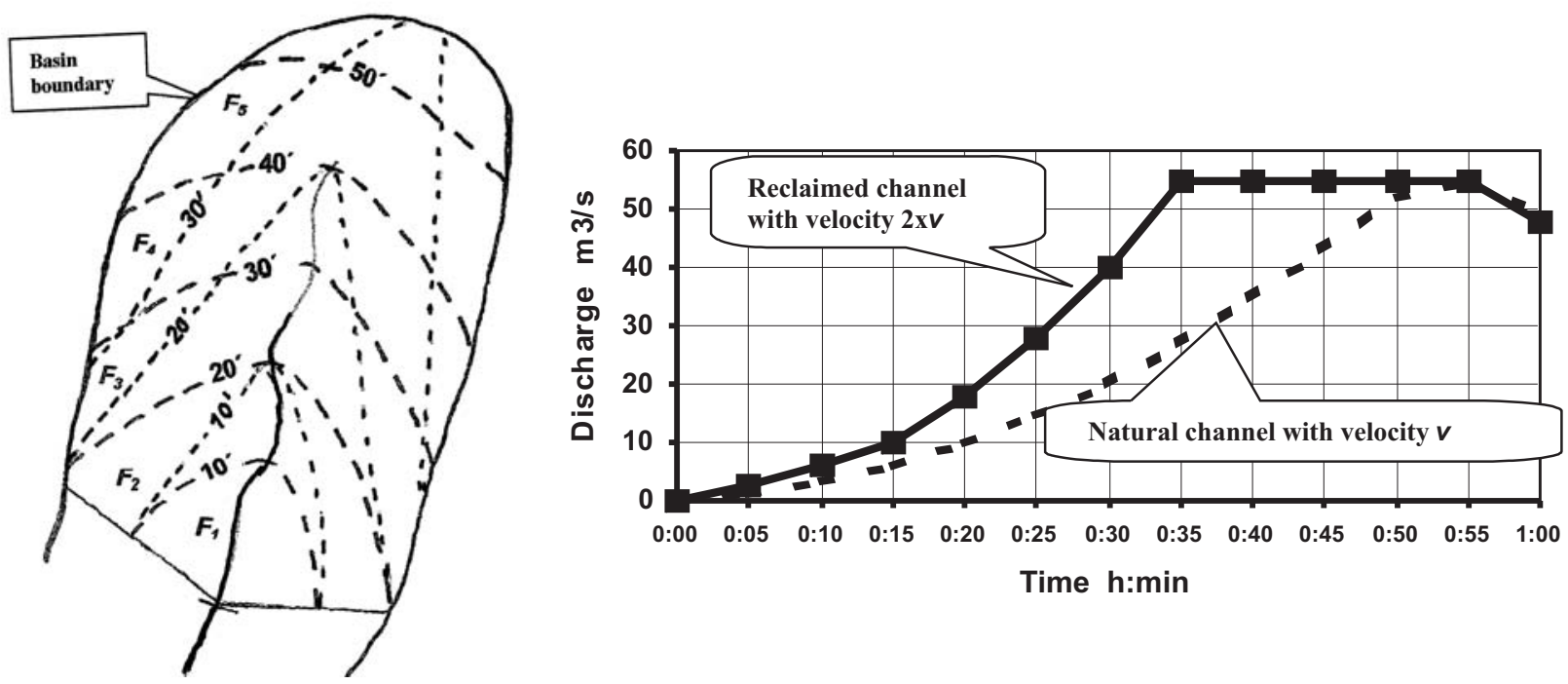

Fig. 2: Comparison of isochrones and hydrographs for two different mean velocities in a channel 


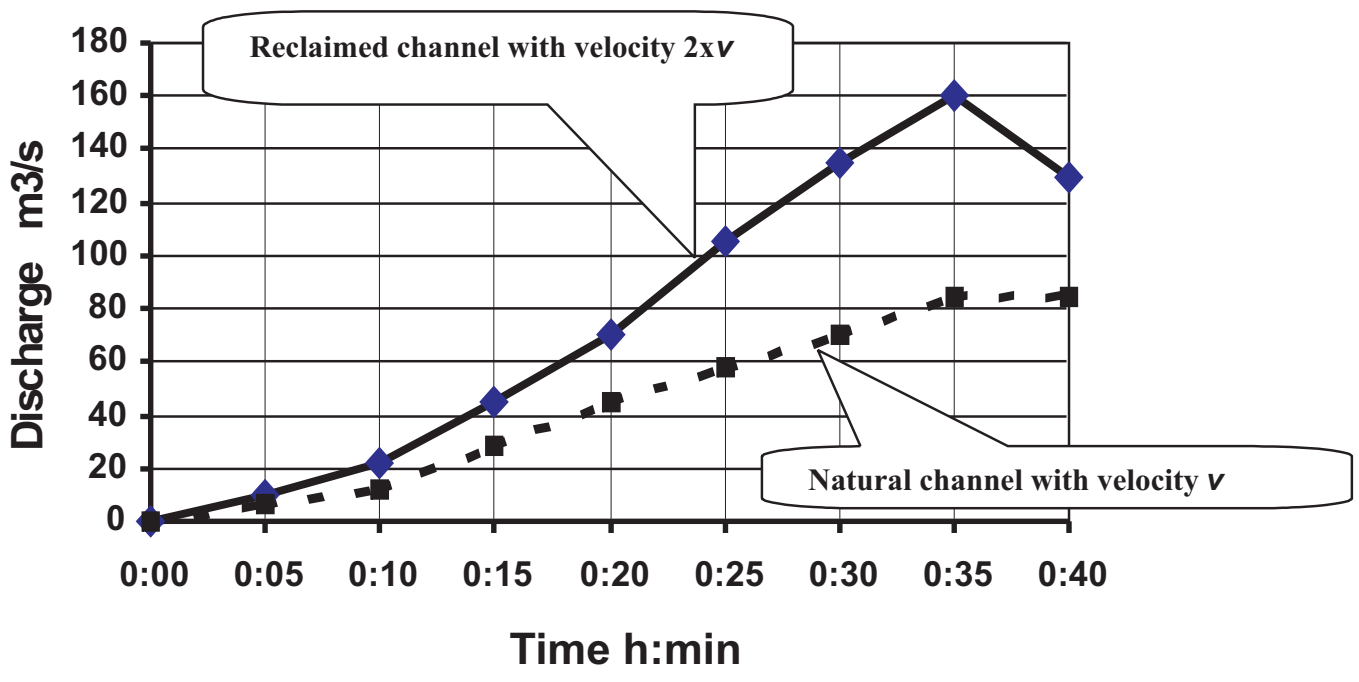

Fig. 3: Comparison of hydrographs of the same watershed for rainfall of duration equal to the concentration time in a reclaimed channel with higher water velocity (precipitation depth $48 \mathrm{~mm}$ and duration $35 \mathrm{~min}$.)

In the first case, the maximum discharge in the outflow profile is reached in 55 minutes, i.e. the concentration time is 55 minutes. This is also the duration of the simulated rainfall (the descending part of the hydrograph starts at time 0:55). The concentration time is much shorter if the channel velocity is two times higher; it is 35 minutes (see Fig. 2). Since the rainfall duration and intensity remain the same in both cases, the maximum discharge has the same value in both cases, only in the adapted channel it passes the outflow profile over a longer time period, namely for 20 minutes (from time 0:35 to 0:55). The application of Eq. 1 shows why the value of the maximum discharge, $Q_{k}$, is the same for both cases. The area of the watershed $F_{t}$ remains unchanged, and the same holds for the coefficient of direct runoff $k_{0}$. The concentration time $t_{k}$ is 55 minutes in the first case and 35 minutes in the other case. In 35 minutes the precipitation depth at the watershed is $H_{35}=\left(H_{55} / 55\right) 35$ and thus

$Q_{k}=F_{t} k_{0} H_{55} \frac{10^{3}}{60 \times 55}=F_{t} k_{0} \frac{H_{55} \times 35}{55} \frac{10^{3}}{60 \times 55}$

Rainfalls of shorter duration have higher intensities (see an example in Table 1). In the region of Hermanuv Mestec, a rainfall event with 50 -year periodicity $(N=50)$ and a duration of 30 minutes produces a precipitation depth of $45.3 \mathrm{~mm}$. If its duration is 60 minutes, the total precipitation depth is $55.0 \mathrm{~mm}$, i.e. $22.5 \mathrm{~mm}$ in 30 minutes. A rainfall event produces a much higher maximum discharge $Q_{k}$ when the concentration time of the watershed is equal to the rainfall duration than when the concentration time is longer than the rainfall duration. To show this effect, Fig. 3 compares the hydrographs for a rainfall of 35-minute duration in a watershed with a concentration time of 35 minute (the watershed with the adapted channel) and 55 minutes (the watershed with the unadapted channel), respectively.

The maximum flow rate in the outflow profile of the reclaimed channel with the velocity twice the velocity in the natural channel is almost two times higher than the maximum flow rate in the natural channel. The hydrograph is also much steeper. The outflow from the watershed with the natural channel is more equally distributed in time. The maximum flow rate corresponding with the flow rate in the time equal to the concentration time is never reached. Water from the farthest locations reaches the outflow profile after the end of the rain event. Since in the watershed the longer concentration time is caused by the natural channel, it is obvious that the channel has a damping effect on the flood wave passing through the natural channel.

Fig. 4 compares the hydrographs in our two channels for rainfalls of a certain periodicity (50 years) and durations corresponding with the concentration times, i.e. for rainfalls with durations of 35 minutes (reclaimed channel) and 55 minutes (natural channel). From Table 1 the rainfalls of periodicity $N=50$ are selected, and thus their precipitation depths are $48 \mathrm{~mm}$ for the 35-minute duration and $52 \mathrm{~mm}$ for the 55-minutes duration. Fig. 4 shows that the channel with the two times higher velocity significantly increases and accelerates the runoff from the watershed. Thus the general

Table 1: Intensity-duration-frequency table of rainfalls in the region of Hermanuv Mestec, Czech Republic

\begin{tabular}{|l|c|c|c|c|c|c|}
\hline Duration & $\boldsymbol{N = \mathbf { 2 }}$ & $\boldsymbol{N = \mathbf { 5 }}$ & $\boldsymbol{N = \mathbf { 1 0 }}$ & $\mathbf{N = \mathbf { 2 0 }}$ & $\boldsymbol{N = \mathbf { 5 0 }}$ & $\boldsymbol{N}=\mathbf{1 0 0}$ \\
\hline $30 \mathrm{~min}$. & 16.9 & 23.5 & 30.1 & 36.8 & 45.3 & 52.0 \\
\hline $40 \mathrm{~min}$. & 18.5 & 26.0 & 33.3 & 40.7 & 50.3 & 58.0 \\
\hline $60 \mathrm{~min}$. & 19.6 & 28.0 & 36.0 & 44.2 & 55.0 & 63.0 \\
\hline $90 \mathrm{~min}$. & 21.2 & 30.0 & 39.0 & 47.9 & 59.6 & 68.3 \\
\hline $120 \mathrm{~min}$. & 22.5 & 32.0 & 41.3 & 50.7 & 63.0 & 72.3 \\
\hline
\end{tabular}




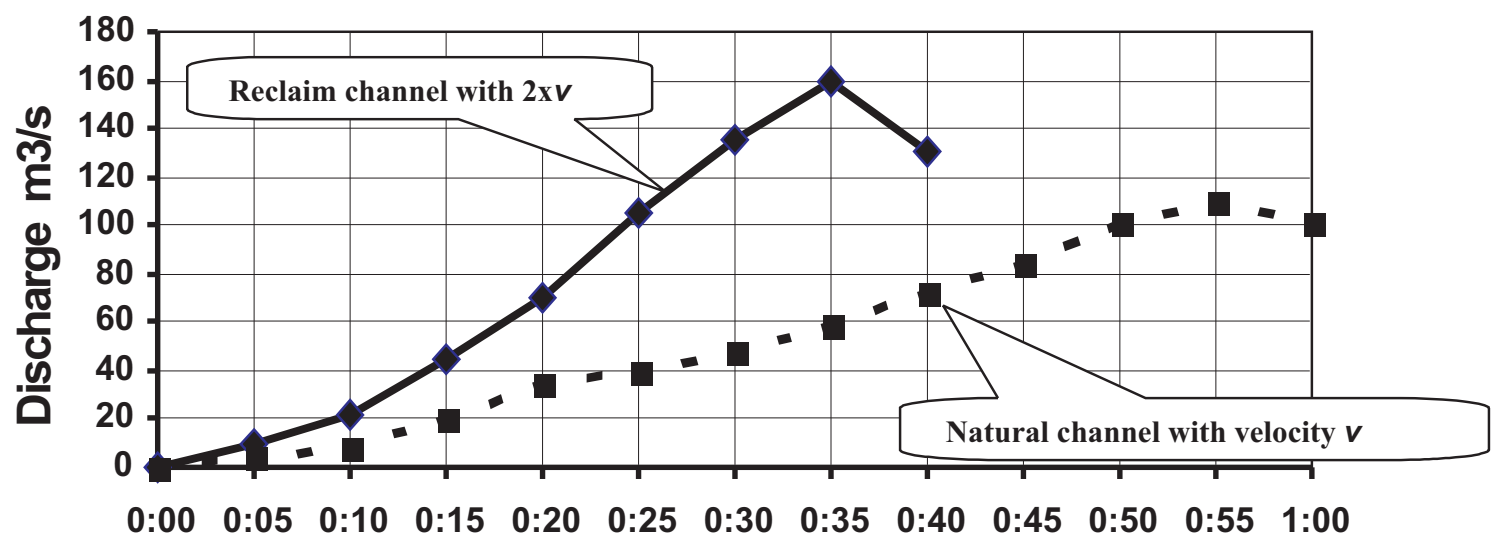

Time h:min

Fig. 4: Comparison of hydrographs of the same watershed for rainfall of periodicity 50 years and duration equal to the concentration time in each watershed (precipitation depth $48 \mathrm{~mm}$ for rainfall duration $35 \mathrm{~min}$ in a watershed with a reclaimed channel and precipitation depth $52 \mathrm{~mm}$ for rainfall duration $55 \mathrm{~min}$ in a watershed with a natural channel)

conclusion is that a channel draining a watershed is able to increase and accelerate the flood wave.

The above analysis, based on the method of isochrones, shows a profound effect of the hydraulic characteristics of a stream channel on the runoff hydrograph. The following step is to demonstrate the results of the analysis on a practical example of an observed flood event.

Remark: In reality, a stream channel with low velocity has a small capacity. Thus during flood events the channel is usually not able to drain all water down the channel. Instead, some water spreads into the floodplains along the channel. This helps to keep the velocity of the flow low. At the same time, the floodplain accumulates water for some time and thus damps the flood wave. The flood wave transforms itself, and becomes flatter and longer. The method of isochrones does not solve the transformation of a flood wave due to the spread of water into the floodplain. There are methods available for solving the transformation. One suitable method will be used below to analyze the observed flood event.

\section{Practical example: a flood event on Dubanka creek on May $30^{\text {th }}, 2005$}

\subsection{Description of the flood event}

In the late afternoon of May $30^{\text {th }}, 2005$ water and mud from the local Dubanka creek flooded the village of Rozhovice, which lies $4 \mathrm{~km}$ from Hermanuv Mestec and $6 \mathrm{~km}$ from Chrudim, in East Bohemia. The Dubanka is a left-side tributary of the small river Bylanka, which joins the Labe river near Pardubice.

The report of the municipality representatives from the June $1^{\text {st }}$, of 2005 describes the flood event as follows:

"The flood event was created by an intensive rainstorm (lasting for 10-15 minutes approximately) accompanied by a hailstorm, strong wind and a thunderstorm. Due to the specific configuration of the landscape and inappropriate exploitation of the land (maize fields) in the watershed of the Dubanka creek above the village of Rozhovice, an extensive runoff of water occurred and the village was flooded.
The surface runoff caused transport of soil and mud from the fields. The sediments covered the streets, gardens, parks, cellars, garages, houses, cars, sewers, wells and the channel of the creek."

The report identifies three reasons for the flood event:

1) rainfall of high intensity,

2) the configuration of the landscape, namely the steep slope of the creek valley,

3) inappropriate agricultural exploitation of the valley slopes (maize fields).

\subsection{Reconstruction of the flood event, and an analysis of its causes}

Information on parameters of the rainfall that caused the flood event was obtained from photos of meteorological radars acquired from the Czech Hydrometeorological Institute. Photos giving local precipitation in 10-minute intervals and photos of one-hour precipitation totals were available.

An analysis of the photos revealed that surprisingly enough, the rain lasted only 30 minutes and the total precipitation depth was only $20 \mathrm{~mm}$. A comparison of this depth with the depths typical for the area (see Table 1) shows that the periodicity of the rainfall is less than 5 years. Such a rainfall should not cause a flood event of the size experienced on May $30^{\text {th }}, 2005$. A field survey revealed that the rainfall was very local. The rain hit the slope of the Dubanka creek valley above the village of Rozhovice. The slope was being exploited as a maize field. Apparently, the affected area was small, but the runoff from the area was very great.

The hydraulic parameters and the longitudinal water-surface slope of the stream channel of the Dubanka creek were measured in a suitable reach behind a culvert just above the village. The channel in the reach was very deep (depth of $1.5 \mathrm{~m}$ ) and had a large longitudinal slope $(2.86 \%)$. Traces on the channel banks and in their surroundings indicated that the channel was full during the flood event and conveyed all the drained water (no traces of a water surface in the floodplain). There were no backwater conditions. The Manning equation gave a mean velocity of about $4 \mathrm{~m} / \mathrm{s}(R=0.62$, $n=0.030)$. The banks and bottom of the channel were lined 
with a stone pavement covered by reeds. The high degree of devastation of the reed vegetation in the channel supported the idea of high velocity in the channel during the flood event. According to the traces, the discharge area of the channel was $3 \mathrm{~m}^{2}$ at the maximum flow rate and thus the maximum flow rate was approximately $12 \mathrm{~m}^{3} / \mathrm{s}$.

The estimated value of the maximum discharge was confirmed by the measurements in a hydraulic structure on the Dubanka creek below Rozhovice. The structure was a small railway bridge that exhibited clear traces of the maximum water level on the front and rear faces of the bridge. This information was processed in the HEC-RAS program, which gave a maximum flow rate of $15 \mathrm{~m}^{3} / \mathrm{s}$. A parallel hydraulic structure, a rectangular culvert $1 \times 1.2 \mathrm{~m}$ in dimensions, conveyed approximately $3.0 \mathrm{~m}^{3} / \mathrm{s}$ of additional flow. Thus the total maximum flow rate in the creek below Rozhovice was about $18 \mathrm{~m}^{3} / \mathrm{s}$. This value corresponds very well with the value of $12 \mathrm{~m}^{3} / \mathrm{s}$ above the village, because the outflow profile above the village drains water from a watershed $1.123 \mathrm{~km}^{2}$ in area while the outflow profile below the village drains an area of $1.68 \mathrm{~km}^{2}$, i.e. an area one-third larger $\left(0.557 \mathrm{~km}^{2}\right)$ than the area above the village.
The landscape of the watershed drained by the Dubanka creek above Rozhovice is described in Fig. 5. The area of the watershed is $1.12 \mathrm{~km}^{2}$. The map shows the steep slopes of the Dubanka valley. The mean left-bank slope is about $7 \%$ and its maximum local value is $14.5 \%$. The mean right-bank slope is about $6 \%$ and the maximum local value $10.4 \%$. Maize should not be grown on such steep slopes.

The rules stipulated by Czech standard CSN 754500 "Erosion control of agricultural land" were not followed when this maize field was sown on the slopes of the Dubanka valley. Not even contour seeding was applied, and the drills were seeded in the downhill direction, as shown in Fig. 6. The downhill directed drills created small natural channels that drained the field during the rainfall event and increased the direct runoff and its velocity. Water flowing through the drills eroded the soil surface and formed deeper rills in which the water velocity increased further and through which the water transported large amounts of eroded soil to the creek.

The maize field was probably able to pond only a small part of the precipitation water, and thus the coefficient of direct runoff must have been high. Information on the rainfall, the maximum flow rate, and the watershed slopes made it

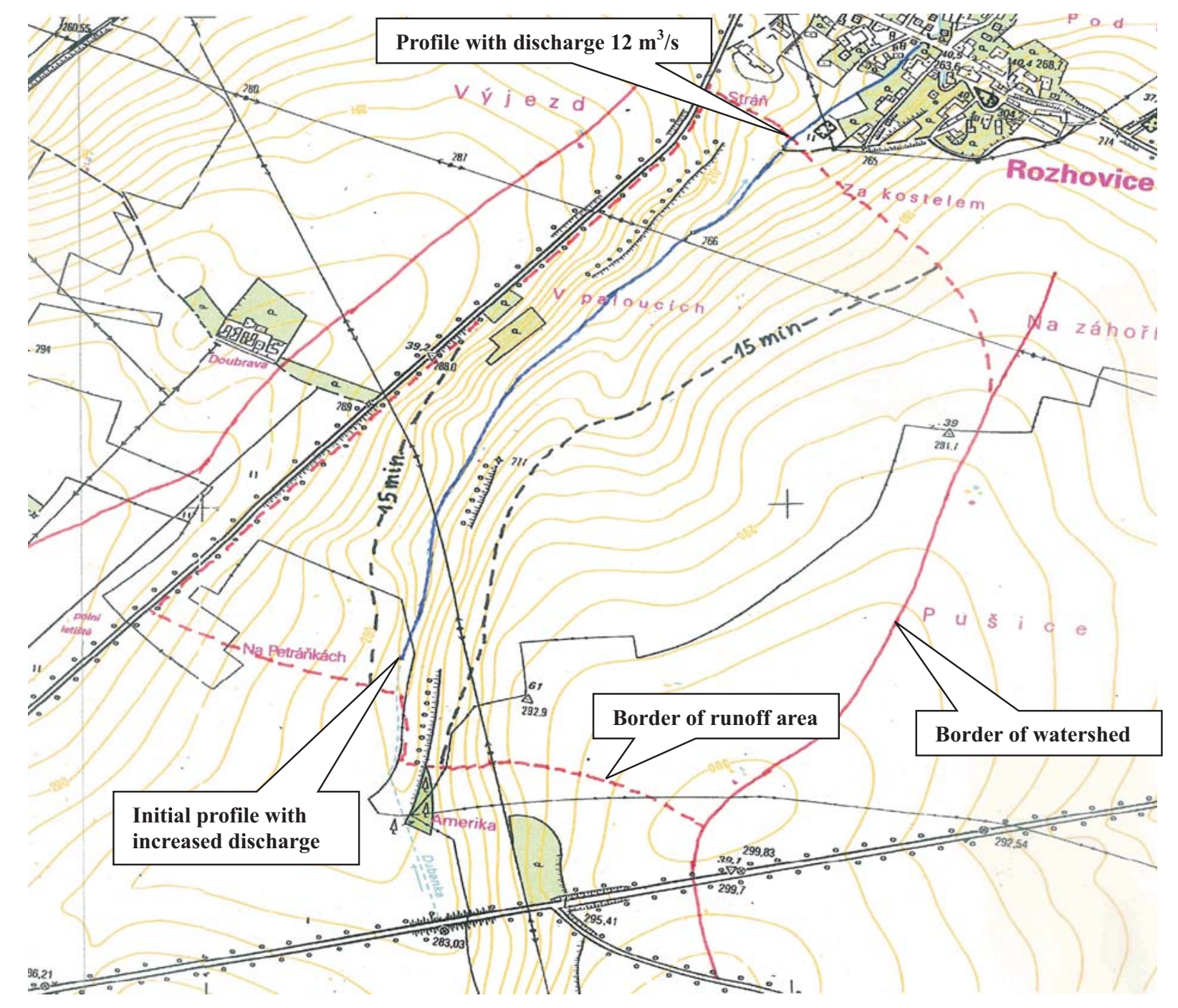

Fig. 5: Map showing isochrones of the Dubanka watershed above Rozhovice 


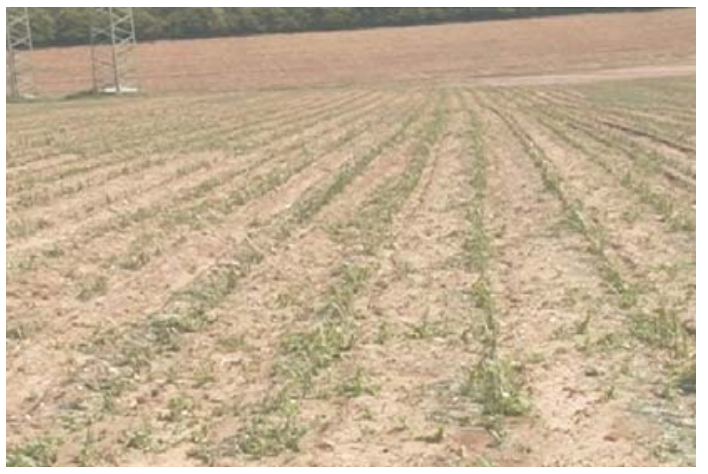

Fig. 6: Maize drills in the downhill direction on a slope of the Dubanka valley

possible to construct the isochrones and calculate the coefficient of direct runoff $\left(k_{0}\right)$. The 15-minute isochrone is drawn in Fig. 5. The concentration time of the entire affected area above the outflow profile in Fig. 5 was 30 minutes. Therefore the value for coefficient $k_{0}$ could be determined using Eq. 1 as

$$
12=1.123 \times 20 \times k_{0} \frac{10^{3}}{60 \times 30},
$$

and thus $k_{0}=0.96$. This is an extremely high value and it indicates that the maize field absorbed virtually no water. This was due to the steep slope and the use of inappropriate drills in the maize field.

Thus the fast runoff of precipitation water from the watershed was a major reason for the extremely high maximum flow rate in the outflow profile just above the village of Rozhovice. However, it is unlikely that it was the only reason. It is necessary to examine what role the stream channel played in the formation of the maximum flow rate. This role was not recognized in the report by the municipality representatives. Apparently, the representatives were not aware of this aspect of the formation of a flood wave. In general, little is known about the role of a stream channel with a hydraulically unsuitable shape in the development of a runoff hydrograph.

\subsection{Evaluation of the role of the hydraulic characteristics of a stream channel}

The channel of the Dubanka creek is virtually straight and smooth (Fig. 7). Moreover, it is deep. It was adapted in the 1930s to drain the surrounding fields. The mean longitudinal slope of the channel is $0.93 \%$. The channel has a trapezoidal cross section with a bottom width of $0.5 \mathrm{~m}$, a bank slope $1: 1$, and a minimum depth of about $1.2 \mathrm{~m}$. The full channel has a discharge area of $2.04 \mathrm{~m}^{2}$ and hydraulic radius $R=0.60 \mathrm{~m}$. The roughness coefficient $n=0.030$ and velocity coefficient $C=30.64$. The Manning equation gives a mean velocity $v=2.3 \mathrm{~m} / \mathrm{s}$ in the full channel. The capacity of the full channel is $Q=2.3 \times 2.04=4.7 \mathrm{~m}^{3} / \mathrm{s}$. There is no vegetation belt along the channel banks that would prevent washing of soil from the surrounding fields into the channel (see Fig. 7). The fields are cultivated down to the upper border of the channel bank and thus the wetted perimeter of the discharged area also remains relatively smooth if the channel is overfull. Due to the straight course of the channel and the small roughness of the surface of the channel and of the channel surroundings, the flow velocity increases during a flood event even if the channel is full and a certain part of the water flows over the bank.

The method of isochrones is used to reconstruct the runoff hydrograph from the May $30^{\text {th }}$, 2005. The investigation described above provided us with the values of the precipitation depths, the direct runoff coefficient and the areas confined by the isochrones. This information is sufficient to determine the flow rates through the outflow profile at various time periods during the flood event, using Eq. 1. After the first 15 minutes of the rainfall the channel at the outflow profile drained the steep-slope part of the watershed area of $0.408 \mathrm{~km}^{2}$. This is a large area, and its size is primarily due to the high velocity of the water in the channel. The precipitation depth on the area after 15 minutes was $10 \mathrm{~mm}$, and estimated 80 per cent of the precipitation water run off. This means $k_{0}=0.8$, which is smaller than the value of 0.96 found earlier. The value of 0.96 is associated with the situation at the end of the rainfall (i.e. 30 minutes after the beginning of the rainfall). Basically, the value of the direct runoff coefficient should increase with the duration of a rain event. After the rain begins, first the soil pores are filled with rainfall water, and interception and surface accumulation takes place, all of these processes inhibiting the direct runoff. Eq. 1 determines the flow rate in the outflow profile 15 minutes after the beginning of the rain as

$$
Q_{15}=0.408 \times 10 \times 0.80 \frac{10^{3}}{60 \times 15}=3.62 \mathrm{~m}^{3} / \mathrm{s} .
$$

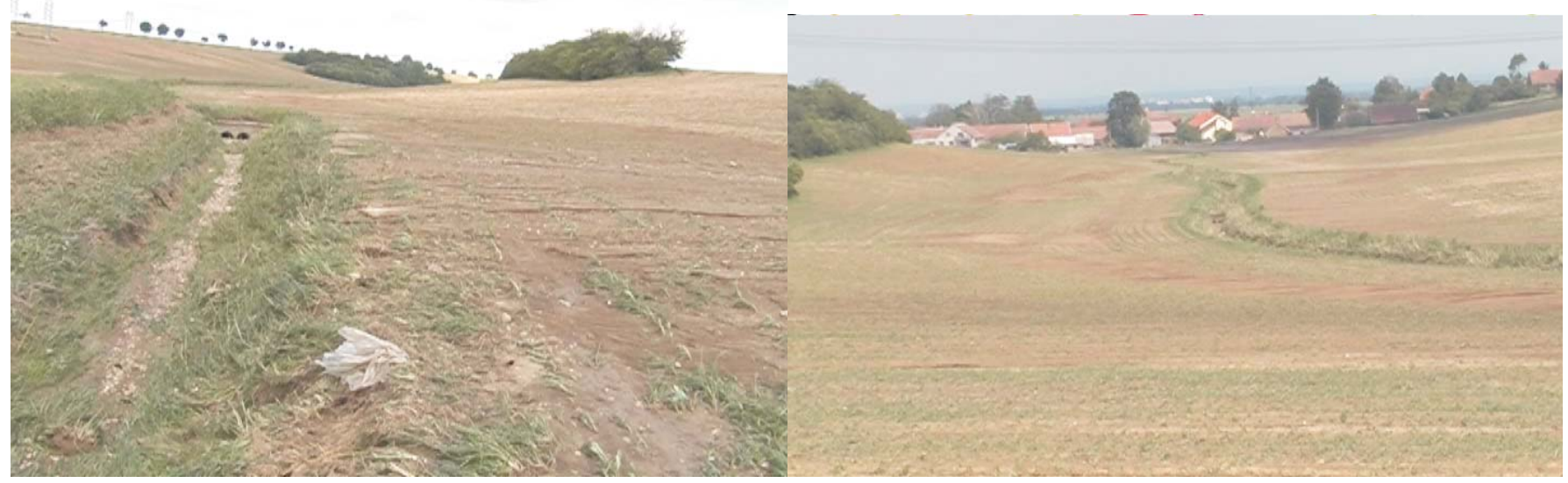

Fig. 7: Reclaimed channel of the Dubanka creek and its surroundings above Rozhovice 
In the 30th minute after the beginning of the rain, the channel in the outflow profile drained the watershed area of $1.123 \mathrm{~km} 2$ and the flow rate in the profile was

$$
Q_{30}=1.123 \times 20 \times 0.96 \frac{10^{3}}{60 \times 30}=11.98 \mathrm{~m}^{3} / \mathrm{s} .
$$

The duration of the rainfall was 30 minutes, thus the hydrograph curve starts to decrease after reaching the $Q_{30}$ value. The constructed hydrograph is shown on Fig. 8. The hydrograph is steep and the maximum flow rate is high. This is because the water drained from the fields and accumulated in the channel reached the outflow profile very quickly, due to the high velocity of the water in the channel. During the flood event virtually the entire water current flowed through the channel (no spilling over the bank), thus all water elements flowed very quickly and even the elements from the farthest locations of the watershed reached the outflow profile in 30 minutes. As discussed theoretically in the previous section, this causes a steep and high flood wave.

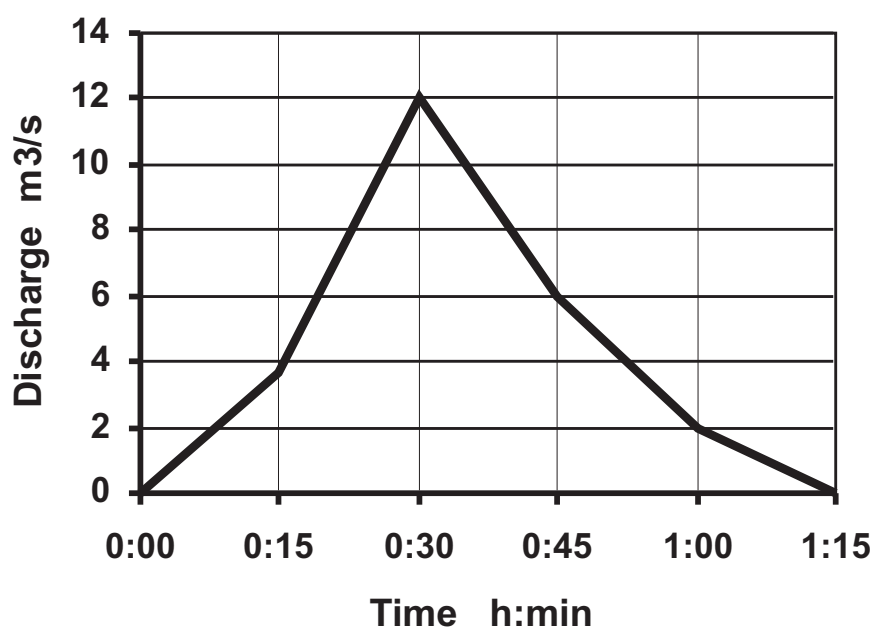

Fig. 8: Deduced hydrograph in the existing channel above Rozhovice during the flood event on May $30^{\text {th }}, 2005$

The reconstruction of the hydrograph of the May $30^{\text {th }}$, 2005 flood event suggests that the role of the properties of the stream channel in the formation of the runoff hydrograph may be important. In addition to the causes recognized in the report by the municipality representatives, a further cause of the flood was the hydraulically inappropriate shape of the reclaimed stream channel. An evaluation of the real impact of the hydraulic characteristics of the stream channel on the hydrograph development requires a simulation and a mutually comparison of the roles of the existing reclaimed channel and of the proposed natural (restored) channel, which has very different hydraulic characteristics.

An inspection of the Dubanka valley indicated how the natural channel of the creek looked before it was adapted seventy years ago. The new proposed natural (restored) channel adopts the properties of the original channel before the adaptation. It is shallow, curved and welted, with a vegetation belt along its banks (Fig. 9).

A cross section of the proposed natural channel is shown in Fig. 10. During a flood event water spills over the banks and flows partially through the floodplain at the bottom of the valley.

The values of the velocities for different water depths and longitudinal slopes are summarized in Table 2. The velocities are small in comparison with the existing channel. This is particularly the case for the maximum flow rate (the velocity was more than $2.3 \mathrm{~m} / \mathrm{s}$ in the existing channel during the flood event, while the velocity in the natural channel would be about $0.5 \mathrm{~m} / \mathrm{s}$ ). This has a significant effect on the distribution of the isochrones in the Dubanka watershed above Rozhovice (see Fig. 11). Remember that the conditions on the slopes of the Dubanka valley are the same for both compared channels, as is the velocity of the water in the maize field. The diminishing velocity is due exclusively to the increased roughness of the discharge perimeter at the bottom of the valley and consequent spilling of water into the floodplain at the bottom of the valley.

The construction of the isochrones and the hydrograph for the Dubanka watershed drained by the proposed natural channel is described in Tables 3-5.

The isochrones in Fig. 11 reveal significant deceleration of the runoff. The time of concentration changed from 30 minutes for the existing channel to 60 minutes for the proposed natural channel. This affects the runoff areas in Table 4 and the hydrograph parameters in Table 5. The maximum discharge is reached at the 45th minute after the beginning of the rain. This discharge is produced by the runoff from the area between the 15-minute isochrone in the 45-minutes isochrone. This area is the largest, and it is logical that it forms

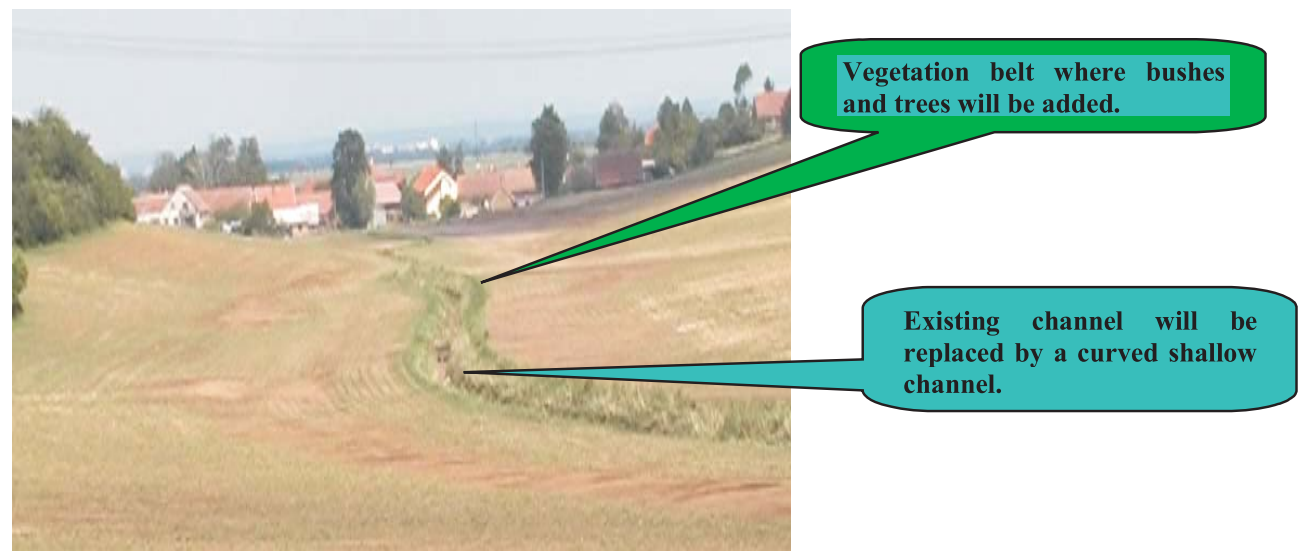

Fig. 9: Proposal for a new natural channel 
Table 2: Velocities and flow rates in the proposed natural channel (Fig. 10) for different water depths and longitudinal slopes $(n=0.10)$

\begin{tabular}{|c|c|c|c|c|c|c|c|c|}
\hline$h$ & $S$ & $O$ & $R$ & $C$ & \multicolumn{2}{|c|}{$v(\mathrm{~m} / \mathrm{s})$} & \multicolumn{2}{c|}{$Q\left(\mathrm{~m}^{3} / \mathrm{s}\right)$} \\
\hline$(\mathrm{m})$ & $\left(\mathrm{m}^{2}\right)$ & $(\mathrm{m})$ & $(\mathrm{m})$ & $\left(\mathrm{m}^{0.5} / \mathrm{s}\right)$ & $1.2 \%$ & $1 \%$ & $1.2 \%$ & $1 \%$ \\
\hline 0.20 & 0.6 & 6.0 & 0.1 & 6.81 & 0.24 & 0.22 & 0.14 & 0.13 \\
\hline 0.40 & 2.4 & 12.0 & 0.2 & 7.64 & 0.35 & 0.34 & 0.84 & 0.82 \\
\hline 0.60 & 5.4 & 18.0 & 0.3 & 8.18 & 0.49 & 0.45 & 2.65 & 2.42 \\
\hline 0.80 & 9.6 & 24.0 & 0.4 & 8.58 & 0.59 & 0.54 & 5.71 & 5.21 \\
\hline 1.0 & 1.0 & 30.0 & 0.5 & 8.91 & 0.96 & 0.63 & 10.35 & 9.45 \\
\hline
\end{tabular}

Table 3: Time development of the flow rate along the length of the natural channel and the distance of the isochrones from the outflow profile

\begin{tabular}{|c|c|c|c|c|c|c|c|c|c|c|}
\hline \multirow{2}{*}{$\begin{array}{c}t \\
(\mathrm{~min})\end{array}$} & $\begin{array}{c}\text { 1st reach } \\
\left(\mathrm{m}^{3} / \mathrm{s}\right)\end{array}$ & $\begin{array}{c}v \\
(\mathrm{~m} / \mathrm{s})\end{array}$ & $\begin{array}{c}L \\
(\mathrm{~m})\end{array}$ & $\begin{array}{c}Q \\
\left(\mathrm{~m}^{3} / \mathrm{s}\right.\end{array}$ & $\begin{array}{c}v \\
(\mathrm{~m} / \mathrm{s})\end{array}$ & $\begin{array}{c}L \\
(\mathrm{~m})\end{array}$ & $\begin{array}{c}Q \\
\left(\mathrm{~m}^{3} / \mathrm{s}\right)\end{array}$ & $\begin{array}{c}\text { 2nd reach } \\
(\mathrm{m} / \mathrm{s})\end{array}$ & $\begin{array}{c}L \\
(\mathrm{~m})\end{array}$ & $\begin{array}{c}\text { Total } \\
\text { length } \\
(\mathrm{m})\end{array}$ \\
\hline 15 & $0-1.5$ aver. $=0.75$ & 0.33 & 297 & & & & & & & 297 \\
\hline 30 & $1.5-5.0 ;$ aver. $=3.3$ & 0.48 & 432 & $0-3.0$ aver. $=1.5$ & 0.39 & 351 & & & & 783 \\
\hline 45 & $5.0-7.0 ;$ aver. $=6.0$ & 0.55 & 495 & $3.0-5.0$ aver. $=4.0$ & 0.50 & 450 & $0-4.0$ aver. $=2.0$ & 0.42 & 378 & 1323 \\
\hline
\end{tabular}

Table 4: Areas between isochrones in the watershed drained by the natural channel

\begin{tabular}{|c|c|c|c|c|c|}
\hline Area & 1 & 2 & 3 & 4 & Total \\
\hline $\mathrm{km}^{2}$ & 0.112 & 0.398 & 0.420 & 0.193 & 1.123 \\
\hline
\end{tabular}

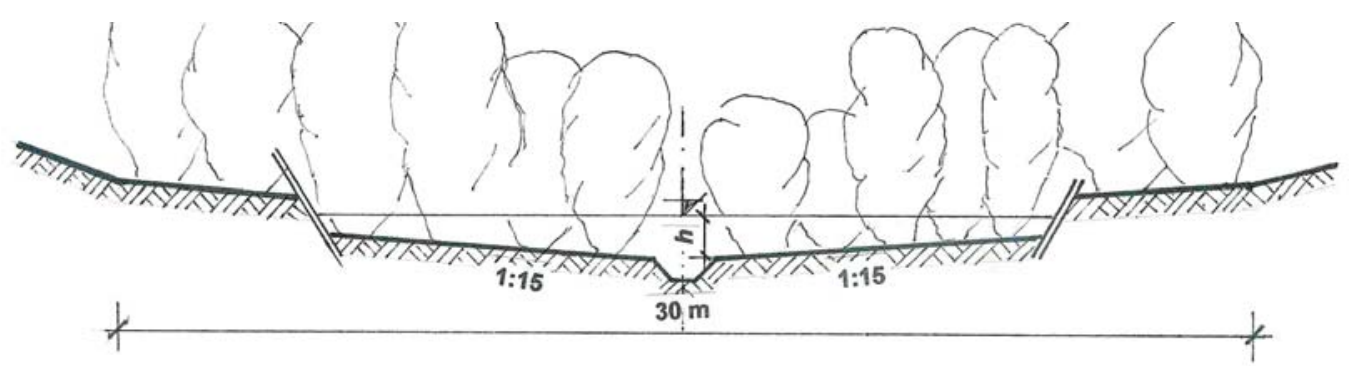

Fig. 10: Cross section of the proposed natural channel and its surroundings

the highest discharge. According to Eq. 1, the runoff from this area is equal to

$Q_{45}=(0.398+0.42) \times 20 \times 0.96 \times \frac{10^{3}}{60 \times 30}=8.64 \mathrm{~m}^{3} / \mathrm{s}$.
This confirms the value reached in Table 5. The maximum flow rate $\left(8.6 \mathrm{~m}^{3} / \mathrm{s}\right)$ is significantly lower than that for the existing channel $(12 \mathrm{~m} 3 / \mathrm{s})$. Thus the presence of the natural channel flattens and prolongs the hydrograph in

Table 5: Hydrograph parameters for the natural channel, using Eq. 1

\begin{tabular}{|c|c|c|c|c|c|c|c|c|c|}
\hline \multirow{2}{*}{$\begin{array}{c}t \\
(\min ) \\
\end{array}$} & \multicolumn{2}{|c|}{ Area 1} & \multicolumn{2}{|c|}{ Area 2} & \multicolumn{2}{|c|}{ Area 3} & \multicolumn{2}{|c|}{ Area 4} & \multirow{2}{*}{$\begin{array}{c}Q_{t} \\
\left(\mathrm{~m}^{3} / \mathrm{s}\right)\end{array}$} \\
\hline & $k_{01}$ & $Q_{1}$ & $k_{02}$ & $Q_{2}$ & $k_{03}$ & $Q_{3}$ & $k_{04}$ & $Q_{4}$ & \\
\hline 15 & 0.90 & 1.12 & & & & & & & 1.12 \\
\hline 30 & 1.00 & 1.24 & 0.90 & 3.98 & & & & & 5.22 \\
\hline 45 & & & 1.00 & 4.42 & 0.90 & 4.20 & & & 8.62 \\
\hline 60 & & & & & 1.00 & 4.67 & 0.90 & 1.93 & 6.60 \\
\hline 75 & & & & & & & 1.00 & 2.14 & 2.14 \\
\hline
\end{tabular}




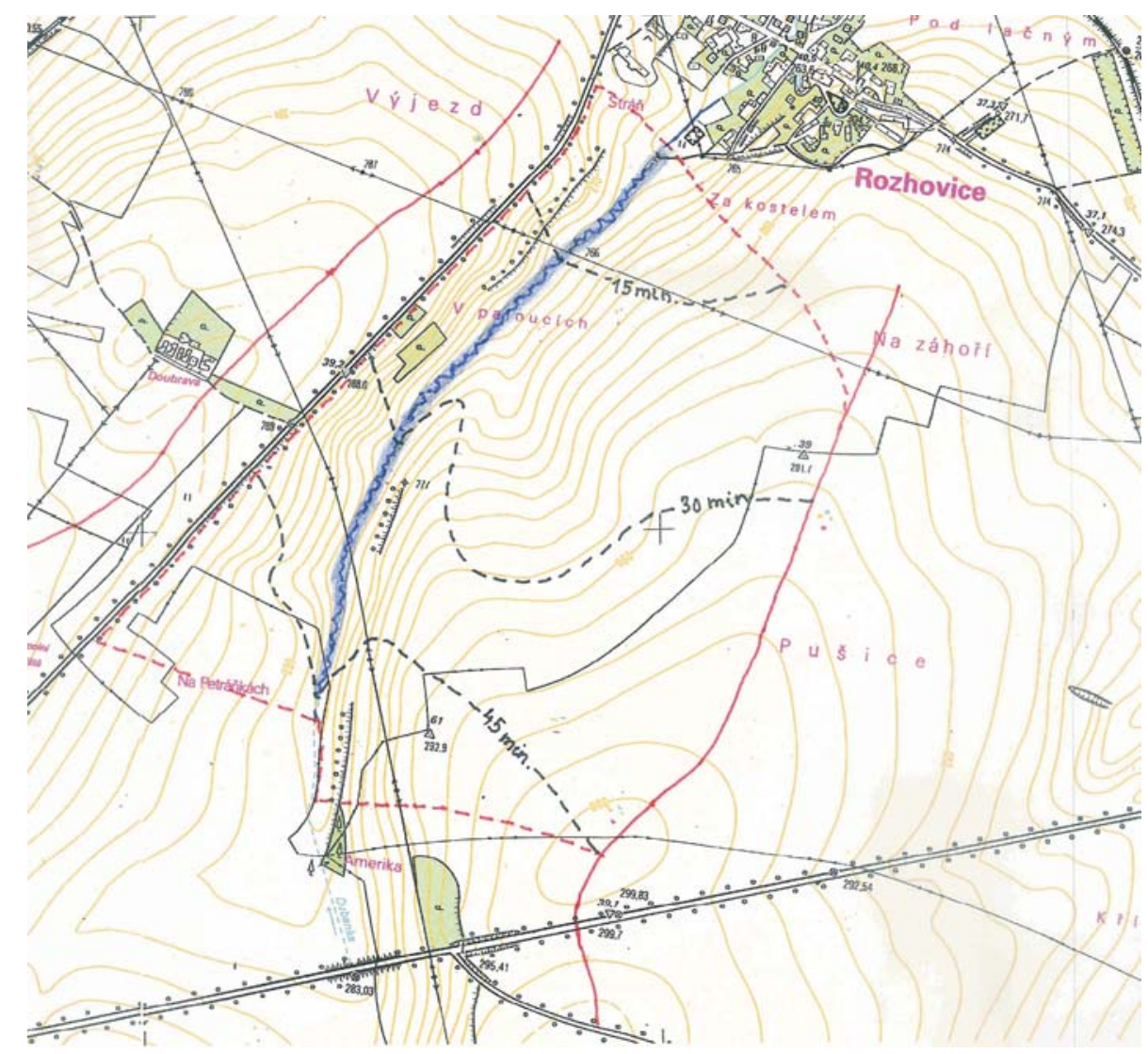

Fig. 11: Map showing the isochrones of the Dubanka watershed drained by the proposed natural channel above Rozhovice

comparison with that for the existing channel. Moreover, there is an additional effect - retention of water in the floodplain at the bottom of the Dubanka valley. This effect is not taken into account in the calculations in Table 5.

\subsection{Evaluation of role of the floodplain in transforming the hydrograph}

The retention takes place in the Dubanka valley drained by the proposed natural channel. The channel has a low capacity of about $0.3 \mathrm{~m}^{3} / \mathrm{s}$ and each flow rate greater than this causes a spillage of water into the floodplain. Thus the valley accumulates water and diminishes the flow rate. This transforms the flood wave, or the hydrograph.

Various methods are available calculating the transformation of a flood wave. The volume balance method is applied here. Water accumulates at the bottom of the valley and forms a temporary lake. There is the flow rate into the lake (inflow $Q_{p}$ ) and out of the lake (outflow $Q_{0}$ ). Over the infinitesimal time period dt the volume Qpdt enters the lake and the volume $Q_{0} \mathrm{~d} t$ leaves the lake. The difference between these two volumes gives the change in the volume of accumulated water in the lake. If $Q_{p}>Q_{0}$, the water depth increases in the lake. Hence

$$
\mathrm{d} V=\left(Q_{p}-Q_{0}\right) \mathrm{d} t=P \cdot \mathrm{d} h,
$$

where $\mathrm{d} V$ is the change in the volume of water accumulated in the lake, $P$ is the area of the water surface in the lake, and $\mathrm{d} h$ is the change in the water depth in the lake. Since we do not have analytical functions for $Q_{p}=f n(t)$ and $Q_{0}=f n(t)$, we are not able to integrate Eq. 3. Instead we can solve the equation

$$
Q_{p} \Delta t-Q_{0} \Delta t=\Delta V
$$

provided that information on $Q_{p}=f_{1}(t), Q_{0}=f_{2}(h)$, and $V=f_{3}(h)$ is available.

The relationship $V=f_{3}(h)$ is found for the geometrical shape and dimensions (read out from a map) of the floodplain at the bottom of the Dubanka valley and it is given in Table 6. Table 6 takes into account the fact that different relations are found between the volume and the depth in the upper reach of the lake (reach 400 metres in length, volume $\mathrm{V}_{2}$ ) and the lower reach of the lake (reach 1000 metres in length, volume $\mathrm{V}_{1}$ ). Table 2 gives $Q_{0}=f_{2}(h)$. For example, if the longitudinal slope is $1 \%$ and the flow rate is $5.21 \mathrm{~m}^{3} / \mathrm{s}$, the water depth in the lake is $0.8 \mathrm{~m}$, according to Table 2 . Table 6 shows that in this case the lake accumulates $11305 \mathrm{~m}^{3}$ of water.

Table 5 gives $Q_{p}=f_{1}(t)$. At time $t=15 \mathrm{~min}$, the total inflow into the lake is $11.23 \mathrm{~m}^{3} / \mathrm{s}\left(1.12 \mathrm{~m}^{3} / \mathrm{s}\right.$ from Area $1 ; 3.98 \mathrm{~m}^{3} / \mathrm{s}$ from Area 2; $4.20 \mathrm{~m}^{3} / \mathrm{s}$ from Area 3, and $1.93 \mathrm{~m}^{3} / \mathrm{s}$ from Area 4). The average flow rate $Q_{p p}$ over the first 15 minutes ( $t$ from 0 to $15 \mathrm{~min}$.) is one half of $11.23 \mathrm{~m}^{3} / \mathrm{s}$, because the flow rate is zero at $t=0$. Over the next 15 minutes ( $t$ from 15 to $30 \mathrm{~min}$.) the inflow is much higher. At $t=30 \mathrm{~min}$, $Q_{p}=12.47 \mathrm{~m}^{3} / \mathrm{s}$ (see Table 5) and $Q_{p p}=(11.23+12.47) / 2=$ $11.85 \mathrm{~m}^{3} / \mathrm{s}$. There is no rain in the time period from 30 to $45 \mathrm{~min}$ and $Q_{p p}=(12.47+0) / 2=6.24 \mathrm{~m}^{3} / \mathrm{s}$.

The method discussed above operates with the simplified input relationships. These are, however, accurate enough to demonstrate the effects of water retention. Higher accuracy of the input relationships could be achieved if the geodetic pa- 
Table 6: Relationship $V=f_{3}(h)$

\begin{tabular}{|c|c|c|c|c|c|c|}
\hline $\begin{array}{c}h \\
(\mathrm{~cm})\end{array}$ & $\begin{array}{c}S_{1} \\
\left(\mathrm{~m}^{2}\right)\end{array}$ & $\begin{array}{c}V_{1} \\
\left(\mathrm{~m}^{3}\right)\end{array}$ & $\begin{array}{c}2 / 3 \times h \\
(\mathrm{~cm})\end{array}$ & $\begin{array}{c}S_{2} \\
\left(\mathrm{~m}^{2}\right)\end{array}$ & $\begin{array}{c}V_{2} \\
\left(\mathrm{~m}^{3}\right)\end{array}$ & $\begin{array}{c}\Sigma V \\
\left(\mathrm{~m}^{3}\right)\end{array}$ \\
\hline 40 & 2.4 & 2400 & 26.7 & 1.07 & 428 & 2828 \\
\hline 50 & 3.75 & 3750 & 33.3 & 1.66 & 665 & 4415 \\
\hline 60 & 5.4 & 5400 & 40.0 & 2.4 & 960 & 6360 \\
\hline 70 & 7.35 & 7350 & 46.7 & 3.25 & 1300 & 8650 \\
\hline 80 & 9.6 & 9600 & 53.3 & 4.26 & 1705 & 11305 \\
\hline 90 & 12.15 & 12150 & 60.0 & 5.4 & 2160 & 14310 \\
\hline 100 & 15.0 & 15000 & 66.7 & 6.67 & 2669 & 17669 \\
\hline
\end{tabular}

rameters of the surface of the floodplain were known and used for calculating $V=f_{3}(h)$ and $Q_{0}=f_{2}(h)$, using some hydraulic software like HEC-RAS.

Table 7 demonstrates the process for determining the flow rate in the outflow profile above Rozhovice. The flow rate is influenced by water retention in the floodplain. The flow rate is determined using the volume-balance method described above.

The flow rate in the outflow profile is determined from $V=f_{3}(h)$, i.e. the volume curve of the retention space, and $Q_{0}=f_{2}(h)$, i.e. the consumption curve of the outflow profile. The known value of the inflow rate and its volume determines the predicted outflow volume and the volume accumulated in the lake in a time step. The accumulated volume is added to the total volume of the accumulated water $\mathrm{R}$ from the previous time step and a new value of $R$ is found for the end of the time step. $R=f_{3}(h)$ gives the value of $h$ for the determined $R$ and $Q_{0 t}=f_{2}(h)$ gives the value of the instant flow rate in the outflow profile. The chosen mean flow rate in the outflow profile must be equal to the average value of the instant flow rates $Q_{0 t}$. This result is often achieved already in the second iteration.

After first 15 minutes the floodplain accumulates $4487 \mathrm{~m}^{3}$ of water and the water depth in the lake grows to $50 \mathrm{~cm}$. The stage-discharge curve determines the outflow discharge $Q_{0 t}=1.5 \mathrm{~m}^{3} / \mathrm{s}$. After another 15 minutes, the volume of the accumulated water is much greater, namely $12110 \mathrm{~m}^{3}$. The water depth is $82 \mathrm{~cm}$ and the outflow discharge from the stage-discharge curve is $5.5 \mathrm{~m}^{3} / \mathrm{s}$. This discharge value is very similar to that calculated in Table 5 .

In Table 7, the time period from $t=30 \mathrm{~min}$ to $t=60 \mathrm{~min}$ is calculated in the shorter time step of 5 minutes in order to avoid errors in the time and magnitude of the maximum flow rate from averaging of the outflow discharge over an excessirely long integration period.

Table 5 determines that the maximum flow rate is reached at time $t=45 \mathrm{~min}$. According to the method of isochrones, the flow rate in the outflow profile is composed of the outflow

Table 7: Determination of instant flow rate Qot in the outflow profile above Rozhovice. The flow rate is influenced by water retention in the Dubanka valley.

\begin{tabular}{|c|c|c|c|c|c|c|c|}
\hline $\begin{array}{c}t \\
(\min )\end{array}$ & $\begin{array}{c}Q_{p p} \\
\left(\mathrm{~m}^{3} / \mathrm{s}\right)\end{array}$ & $\begin{array}{c}V_{p} \\
\left(\mathrm{~m}^{3}\right)\end{array}$ & $\begin{array}{c}Q_{0 p} \\
\left(\mathrm{~m}^{3} / \mathrm{s}\right)\end{array}$ & $\begin{array}{c}\mathrm{V}_{0} \\
\left(\mathrm{~m}^{3}\right)\end{array}$ & $\begin{array}{c}R \\
\left(\mathrm{~m}^{3}\right)\end{array}$ & $\begin{array}{c}h \\
(\mathrm{~cm})\end{array}$ & $\begin{array}{c}Q_{0 t} \\
\left(\mathrm{~m}^{3} / \mathrm{s}\right)\end{array}$ \\
\hline 15 & 5.615 & 5054 & 0.75 & 675 & 4379 & 50 & 1.5 \\
\hline 30 & 11.85 & 10665 & 3.5 & 3150 & 11894 & 82 & 5.5 \\
\hline 35 & 10.39 & 3117 & 5.95 & 1785 & 13226 & 86 & 6.4 \\
\hline 40 & 6.23 & 1869 & 6.4 & 1920 & 13175 & 86 & 6.4 \\
\hline 45 & 2.08 & 624 & 6.05 & 1815 & 11984 & 82.5 & 5.7 \\
\hline 50 & 0 & 0 & 5.2 & 1560 & 10424 & 77 & 4.7 \\
\hline 55 & 0 & 0 & 4.3 & 1290 & 9230 & 72 & 4.0 \\
\hline 60 & 0 & 0 & 3.7 & 1110 & 8120 & 68 & 3.4 \\
\hline 75 & 0 & 0 & 2.8 & 2520 & 5600 & 56 & 2.0 \\
\hline 90 & 0 & 0 & 1.6 & 1440 & 4160 & 48 & 1.3 \\
\hline 105 & & & 1.1 & 990 & 3170 & 42 & 0.9 \\
\hline
\end{tabular}

Legend: $Q_{p p}$ - average inflow discharge over time interval, $V_{p}$ - inflow volume, $Q_{0 p}$ - average outflow discharge over time interval, $V_{0}$ - outflow volume, $R$ - total volume of accumulated water in the flood plain, $h$-water depth in the lake of accumulated water, $Q_{0 t}$ - instant outflow discharge in time $t$ 
discharge from Area 2 in the time period from 15 to $30 \mathrm{~min}$, and of the outflow discharge from Area 3 in the time period from 0 to $15 \mathrm{~min}$. The maximum flow rate in the outflow profile is $8.6 \mathrm{~m}^{3} / \mathrm{s}$.

The water retention in the lake has a significant effect on the outflow discharge in the time period from 30 minutes to 45 minutes, because the water depth is great $(82-86 \mathrm{~cm})$, the lake is wide $(24.6-25.8 \mathrm{~m})$, and an increase in the depth by $5 \mathrm{~cm}$ represents an accumulated volume of $1260 \mathrm{~m}^{3}$ in the 1000-m long reach of the lake. An average inflow discharge of $1.4 \mathrm{~m}^{3} / \mathrm{s}$ is required to fill the volume in 15 minutes. If the average inflow discharge is distributed to the triangle hydrograph, then the inflow discharge required to fill the volume is $2.8 \mathrm{~m}^{3} / \mathrm{s}$.

This line of reasoning documents that even a small accumulation significantly damps the flood wave, i.e. diminishes the maximum flow rate. The maximum flow rate is diminished from $8.6 \mathrm{~m}^{3} / \mathrm{s}$ to $6.4 \mathrm{~m}^{3} / \mathrm{s}$, i.e. to 74 per cent of the original flow rate.

Water retention changes the shape of a runoff hydrograph, in particular its descending part. Accumulated water flows out of a floodplain over a longer time period during a floodplain drawdown. Fig. 12 compares of the runoff hydrographs of two different channels for the conditions of the Dubanka flood event on May $30^{\text {th }}, 2005$. The proposed natural channel with a vegetation belt along the channel banks exhibits a much flatter and longer hydrograph than the existing reclaimed channel.

It is important that the hydrograph in the proposed natural channel is flatter. The existing channel in Rozhovice has a capacity of about $8 \mathrm{~m}^{3} / \mathrm{s}$, and thus there would be no flooding in the village if the channel above the village was natural (restored) instead of reclaimed as it is now. Slower grow of the water depth would enable cleaning of the channel during the flood event, and would avoid blockage of the discharge area of the channel at critical locations (hydraulic structures such as culverts, small bridges etc.) During the Dubanka flood event, the flooding of the village was worsened by a culvert that was blocked by debris brought by the flood wave. The blockage caused a further increase in the water level in the village. The culvert was blocked by old wooden window frames washed away from a warehouse belonging to a company that makes windows.

\section{Discussion of results}

Fig. 12 demonstrates the effect of the stream channel and its surroundings on the runoff hydrograph of the Dubanka flood event on the May $30^{\text {th }}, 2005$. The discussion focuses on the effects of any variations in the coefficient of the direct runoff and in the concentration time of the watershed on the course of the flood caused by the rainfall from the May $30^{\text {th }}, 2005$.

\subsection{Effect of maize in a sloping terrain on the direct runoff coefficient}

The presence of the maize field on the slopes of the Dubanka valley affected the course of the flood primarily through the value of the direct runoff coefficient, i.e. through the velocity of the runoff. This was high due to the presence of the maize field. The slope of the valley affected the flood through the value of the direct runoff coefficient and also through the acceleration of the runoff, i.e. through the enlargement of the areas between the isochrones. A combination of the effects of the presence of the maize field and the slope of the valley caused the extremely high value of the coefficient $\left(k_{0}=0.96\right)$.

The effects on runoff from agriculturally cultivated lands of areas smaller than $10 \mathrm{~km}^{2}$ affected by torrential rains can be evaluated using the curve number $(\mathrm{CN})$ method established by the USDA Soil Conservation Service in the United States. A CN curve gives a proportion between the rainfall and the direct runoff, and hence the direct runoff coefficient. This method does not take the slope into account, but works

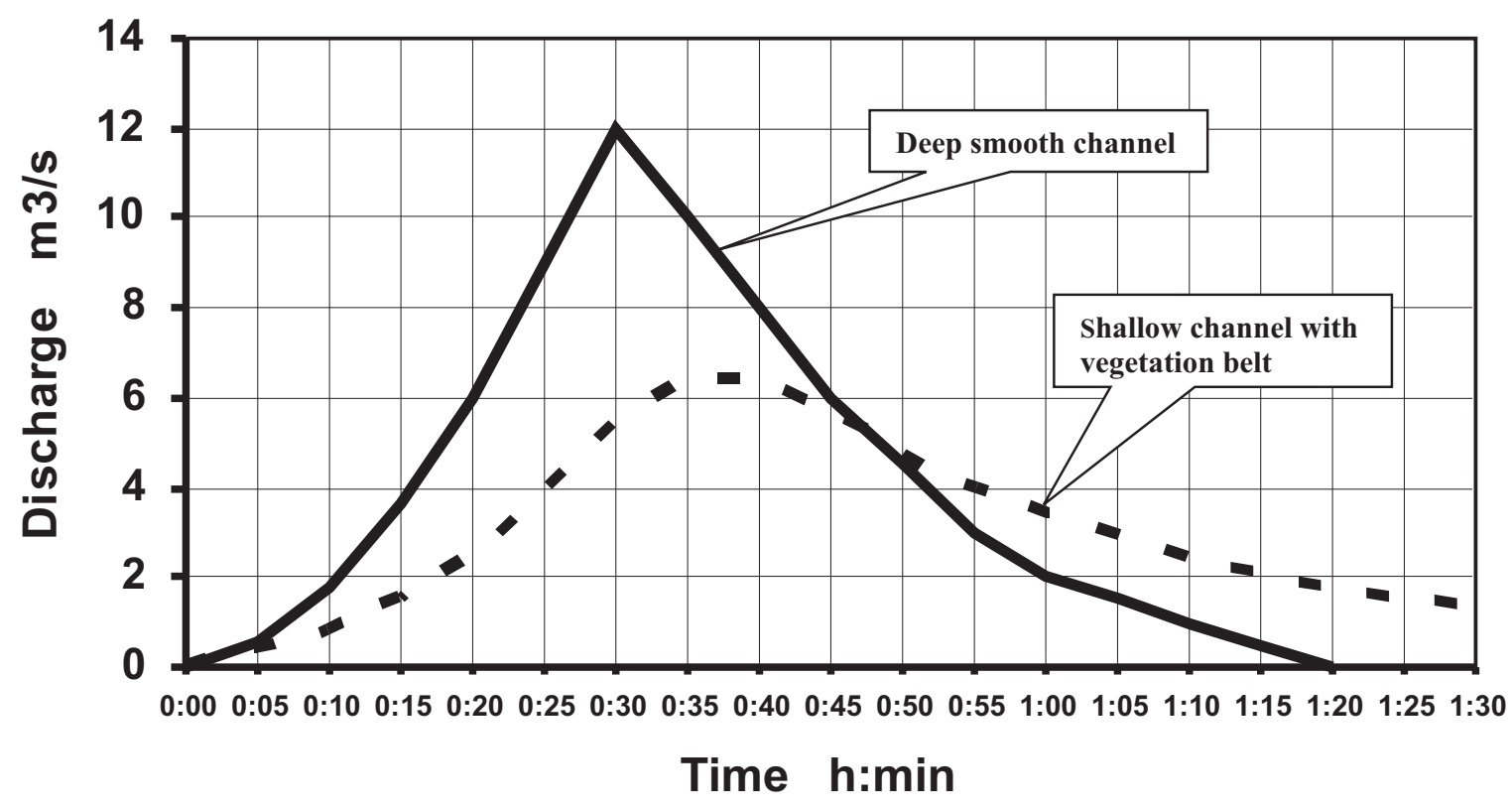

Fig. 12: Comparison of hydrographs for two different channels in the Dubanka valley above Rozhovice. The hydrograph is caused by rainfall of 30-minutes duration and total precipitation of $20 \mathrm{~mm}$ 
only with information about field exploitation, soil cultivation, hydrological conditions and soil infiltration conditions. It gives the value $\mathrm{CN}=91$ for wide-space crops with downhill directed drills and bad hydrological conditions on soil with a very low velocity of infiltration. For a $20-\mathrm{mm}$ rainfall events, this curve corresponds with the coefficient of direct runoff $k_{0}=0.33$, which is a very low value. The value $\mathrm{k}_{0}=0.8$ is not reached until a precipitation depth of $120 \mathrm{~mm}$. If $\mathrm{k}_{0}=0.33$ is correct then the effect on the runoff of the slope of the valley is more important than the effect of the presence of the maize field.

The danger of a steep slope is stressed in every textbook about erosion control on agricultural land. According to Czech standard CSN 754500 "Erosion Control of Agricultural Land", wide-space crops should be raised on fields with slopes not steeper than $8 \%$. For slopes between $8 \%$ and $15 \%$, belts of wide-space crops should be combined with belts of cereals, cereals with underseeding, or perennial fodder plants to impair erosion.

The effect of the downhill orientation of the drills is probably not very important. If the drill were not oriented downhill, the ko value would drop to say 0.8 , and the maximum discharge from $12 \mathrm{~m}^{3} / \mathrm{s}$ to $10 \mathrm{~m}^{3} / \mathrm{s}$.

\subsection{Effect of concentration time on the shape of the runoff hydrograph}

The proposed natural channel prolonged the concentration time from 30 minutes for the existing channel to $60 \mathrm{~min}$ - utes. In the previous sections, it was shown that a rainfall of 30-minutes duration (i.e. a duration equal to the concentration time of the existing channel) significantly flattens the hydrograph. It is necessary to show that this hydrograph flattening also takes place for rainfalls of longer duration, e.g. a duration equal to the concentration time of the proposed channel, i.e. 60 minutes.

According to Table 1, rainfall of 4-year periodicity and 60-min duration gives a precipitation depth of $25 \mathrm{~mm}$. For the existing channel and conditions from May $30^{\text {th }}, 2005$ in the Dubanka valley (maize field with $\mathrm{k}_{0}=0.96$, deep smooth channel, no vegetation belt), the drained area of the outflow profile above Rozhovice after 15 minutes of rainfall is $0.408 \mathrm{~km}^{2}$ and the outflow discharge

$$
Q_{15}=0.408 \times 6.25 \times 0.8 \frac{10^{3}}{60 \times 15}=2.3 \mathrm{~m}^{3} / \mathrm{s} .
$$

After another 15 minutes $(t=30 \mathrm{~min})$ the drained area is $1.123 \mathrm{~km}^{2}$ and the outflow discharge

$$
Q_{30}=1.123 \times 12.5 \times 0.96 \frac{10^{3}}{60 \times 30}=7.5 \mathrm{~m}^{3} / \mathrm{s} .
$$

This flow rate will be maintained for the rest of the rain duration (see Fig. 13).

The determination of the hydrograph for the proposed natural channel is shown in Table 8 . The areas between the isochrones are taken from Table 4 . The maximum flow rate in the outflow profile above Rozhovice is virtually the same as for the existing channel. It changes, however, if the effect of water

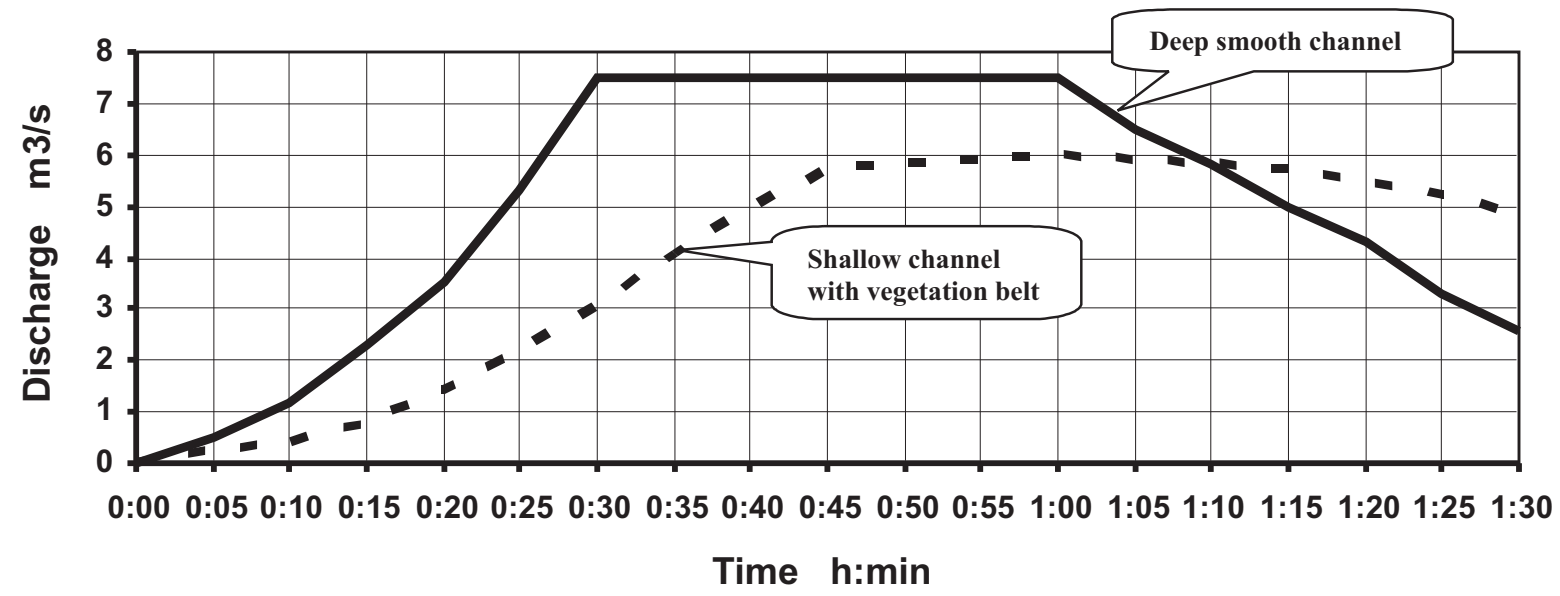

Fig. 13: Comparison of the hydrographs for two different channels in the Dubanka valley above Rozhovice. The hydrographs are caused by rainfall of 60-minutes duration and total precipitation of $25 \mathrm{~mm}$

\begin{tabular}{|c|c|c|c|c|c|c|c|c|c|}
\hline \multirow{2}{*}{$\begin{array}{c}t \\
(\min )\end{array}$} & \multicolumn{2}{|c|}{ Area 1} & \multicolumn{2}{|c|}{ Area 2} & \multicolumn{2}{|c|}{ Area 3} & \multicolumn{2}{|c|}{ Area 4} & \multirow{2}{*}{$\begin{array}{c}Q_{t} \\
\left(\mathrm{~m}^{3} / \mathrm{s}\right)\end{array}$} \\
\hline & $k_{01}$ & $Q_{1}$ & $k_{02}$ & $Q_{2}$ & $k_{03}$ & $Q_{3}$ & $k_{04}$ & $Q_{4}$ & \\
\hline 15 & 0.92 & 0.7 & & & & & & & 0.7 \\
\hline 30 & 1.0 & 0.8 & 0.92 & 2.5 & & & & & 3.3 \\
\hline 45 & 1.0 & 0.8 & 1.0 & 2.8 & 0.92 & 2.7 & & & 6.3 \\
\hline 60 & 1.0 & 0.8 & 1.0 & 2.8 & 1.0 & 2.9 & 0.92 & 1.2 & 7.7 \\
\hline 75 & & & 1.0 & 2.8 & 1.0 & 2.9 & 1.0 & 1.3 & 7.0 \\
\hline
\end{tabular}

Table 8: Determination of the hydrograph for the proposed channel, using Eq. 1 for rainfall of 60 min and 25 mm (no water retention) 
retention is applied. The effect is very similar to that for the 30-min rainfall in the natural channel, because for both rains the maximum flow rate in the natural channel is about $8 \mathrm{~m}^{3} / \mathrm{s}$ for the hydrograph constructed for no retention effect. For the 30-min rainfall the retention effect diminished the maximum flow rate from $8.6 \mathrm{~m}^{3} / \mathrm{s}$ to $6.4 \mathrm{~m}^{3} / \mathrm{s}$ (see Table 7 ). For the 60-min rainfall the retention effect diminishes the maximum flow rate from $7.7 \mathrm{~m}^{3} / \mathrm{s}$ to $6.0 \mathrm{~m}^{3} / \mathrm{s}$ (see Fig. 13).

The comparison of the hydrographs in Fig. 13 shows that the difference between the flood waves for the two different channels is smaller for the rainfall of 60-min duration than for the rainfall of 30-min duration (in Fig. 12). However, the difference is significant for both rains. The smaller difference for the longer-lasting rainfall is because the longer-lasting rainfall has lower intensity, which reduces the adverse effects of the fast runoff promoted by the deep smooth channel.

The comparisons of the hydrographs in Figs. 12 and 13 are actually not completely appropriate. This is because the figures do not compare flood events that produce the maximum flow rate for the given conditions. A flood event generates the maximum flow rate if the flood is caused by rainfall of duration equal to the concentration time of the watershed. Thus, the two hydrographs that should be compared with each other are the hydrograph caused by rainfall of $20 \mathrm{~mm}$ and $30 \mathrm{~min}$ for the existing channel (Fig. 12) and the hydrograph caused by rainfall of $25 \mathrm{~mm}$ and $60 \mathrm{~min}$ for the proposed natural channel (Fig. 13). This comparison shows that the maximum flow rate in the proposed channel is one half of the maximum flow rate in the existing adapted channel.

Theoretically, the maximum flow rate generated in the watershed with the proposed natural channel should be higher for the longer lasting rain (25 $\mathrm{mm}$ and $60 \mathrm{~min}$ ) than for the shorter lasting rain (20 $\mathrm{mm}$ and $30 \mathrm{~min})$. However, Figs. 12 and 13 show that this is not the case for our conditions. The shorter rain produces a maximum flow rate that is $0.4 \mathrm{~m}^{3} / \mathrm{s}$ greater than that produced by the longer rain. This disproportion is due to the specific configuration of the watershed terrain in the Dubanka valley above Rozhovice. The areas confined by the isochrones of 15 and $30 \mathrm{~min}$, and by the isochrones of 30 and 45 min are large in comparison with the areas between other isochrones, and hence rainfall with duration of 30 minutes produces an extraordinarily great runoff.

\section{Conclusions}

The effect of a stream channel and of its floodplain on the course of a flood is described using a comparison of runoff hydrographs for a certain rainfall impacting a certain watershed that is drained by channels with different hydraulic characteristics. The paper proposes a methodology for evaluating the flood waves produced by different (either reclaimed or natural/restored) stream channels. The methodology adopts the method of isochrones for evaluating the effect of the channel itself and the volume balance method for the effect of its floodplain.

The proposed methodology is demonstrated on a flood event that took place in 2005, and shows that restoration of the channel should significantly diminish the maximum discharge produced in the stream channel. If the existing reclaimed hydraulically smooth channel was replaced by the restored channel, the maximum discharge would be reduced to approximately one half. The change in the shape of the runoff hydrograph (and thus the value of the maximum discharge) depends primarily on the change in the velocity of flow through the channel. For the evaluated flood event, the proposed restoration of the stream channel would diminish the velocity from a value of $2.3 \mathrm{~m} / \mathrm{s}$ in the existing reclaimed channel to $0.5 \mathrm{~m} / \mathrm{s}$ in the proposed restored channel. Besides the changes in the hydraulic characteristics of the stream channel, the runoff hydrograph of the observed watershed is further modified due to the effect of the spread of water into the floodplain. The methodology also takes this effect into account.

The methodology shows that reclaimed channels, which are usually deep, straight and smooth, accelerate and increase floods. This is because increased velocity of flow through a channel shortens the time of concentration of the runoff from a watershed. It is well known that the maximum discharge of the runoff is produced by rainfall equal in duration to the concentration time of the affected watershed. Due to a certain constant periodicity of a rainfall event, rainfalls of shorter duration are more intensive and thus produce floods with higher maximum discharges if they impact watersheds with a shorter concentration time equal to the rainfall duration.

\section{Reference}

[1] Ponce, V. M.: Engineering Hydrology. New Jersey: Prentice-Hall, 1989, $640 \mathrm{p}$.

[2] Alberta Environmental Protection, 1999 Stormwater Management Guideline for the Province of Alberta.

[3] WMO, Guide to Hydrological Practices. WMO 1994 No. 168.

[4] ČSN 754500 Erosion control of agricultural land (in Czech).

[5] Kemel, M.: Climatology, meteorology, hydrology. CTU Prague, 2000 (in Czech).

[6] Matoušek, V.: Documentation and evaluation of a flood event on the Dubanka creek. Research report MZP 0002071101, Prague: VúV 2005 (in Czech).

[7] Matoušek, V.: Impact of the Strean Channel and Floodplain on the Course and Magnitude of a Flood. In Just et al.: Water-engineering revitalizations and their applications in flood control, Prague: Artedit, 2005 (in Czech).

[8] USDA Soil Conservation Service, SCS National Engineering Handbook, Section 4: Hydrology. Washington, D.C., 1985

Ing. Václav Matoušek, DrSc.

phone: 220197382

fax: 233333804

e-mail:vaclav_matousek@vuv.cz

Výzkumný ústav vodohospodářský T. G. Masaryka

veřejná výzkumná instituce

Podbabská 2582/30

16000 Praha 6, Czech Republic 